\title{
Research of Mixed Teaching Design Technology
}

\author{
Jun Li, Xu Liang, Xia Li, Xiumei Li
}

Zibo Normal College, Zibo, Shandong, 255130

Keywords: Mixed teaching Method, Teaching Reform, MOOC

\begin{abstract}
In-depth investigation and research is conducted on the existing mixed teaching mode, some exploration and practice of the mixed teaching reform in the MOOC environment is studied. This paper introduces the MOOC platform into the teaching of programming courses, organically integrating the traditional classroom teaching and MOOC teaching modes, and establishing a teaching mode based on "flipped classroom". Through the teaching practice, the teaching effect of the new teaching mode is verified, and constructive opinions are proposed for the mixed teaching of other courses.
\end{abstract}

\section{Introduction}

In the past studies of educational technology, Blending Learning is the most similar expression to mixed teaching. For example, Yu Shengquan et al., Zhang Qiliang and many other researchers use mixed learning and mixing when using the term Blending Learning. The concept of teaching is directly equivalent; Singh et al. use five "appropriate" in the definition of mixed learning, emphasizing that the goal is to obtain optimal learning results, and focus the focus of mixed learning on the subject of learning. --student. Different from hybrid learning, Mixed teaching starts from the dominant position of teachers and focuses on how to help students achieve optimal learning results. Based on the above definition of the concepts of hybrid learning and blended instruction, this study suggests that: Mixed teaching means providing resources and activities that are appropriate to the appropriate learning environment by applying appropriate media technologies at the appropriate time. Appropriate students develop appropriate abilities to achieve a teaching method that optimizes teaching outcomes.

\section{The theoretical basis of Mixed teaching}

The education and teaching personnel training model originated from the factory standardization and streamlined production thought is a teaching that requires standardized teaching materials, unified teaching methods, unified teaching media and standardized evaluation methods in a specified time. process. In the process of instructional design, teachers are forced to choose a medium-level student group as a reference to carry out activities such as instructional design, teaching process arrangement and teaching evaluation. The result will inevitably lead to learning differences and score differentiation among students. The normal distribution curve of student achievement differentiation in turn continues to strengthen the teacher's instructional design, and ultimately forms a vicious circle of instructional design and learning outcomes. However, if teaching is a purposeful, conscious activity and fruitful, then students' academic performance should be a skewed distribution, that is, the majority of students with normal intelligence can achieve excellent or even excellent academic performance. Based on the above understanding, Bloom's mastery of learning theory believes that almost all students can reach almost all the content as long as they give enough time and proper teaching. After mastering the theory of learning, the education circles of the world have conducted large-scale mastery of learning experiments. However, due to the limitations of the conditions at that time, the contradiction between unified teaching and individual learning needs of students cannot be completely solved, especially the learning needs of outstanding students. Unable to be satisfied, and the development of the theory is at a standstill. Today, more than half a century later, the natural advantages of information 
technology to meet the learning needs of students are evident. Mastering learning theory provides a solid theoretical foundation for the teaching of mixed teaching, especially the pre-class knowledge transfer stage.

Bloom divides the dimensions of the cognitive process into six levels: memory, understanding, application, analysis, evaluation, and creation. Observing the current classroom teaching, we can find that most of the teachers' teaching time is still in how to help students to realize the memory, retelling or simple description of knowledge, that is, shallow learning activities. High-order thinking activities such as "application, analysis, evaluation and creation", which focus on the comprehensive application of knowledge and the creative solution of problems, have not received enough attention in current classroom teaching. Based on the critique of isolated memory and mechanical problem solving methods, the deep learning theory researchers propose that teachers should regard the development of high-order thinking ability as a dark line of teaching objectives and accompany classroom teaching. In most classroom teaching today, students need less helpful shallow learning activities that occur in the classroom where teachers exist. When students try to carry out in-depth learning such as knowledge transfer, decision making, and problem solving, they find I am isolated and helpless. Based on this, the Mixed teaching represented by the flipping classroom reverses the original teaching structure, that is, the shallow knowledge learning takes place before the class, and the internalization of knowledge is realized in the classroom with the teacher guidance and help. Promote the improvement of students' high-level thinking ability.

\section{Mixed teaching design method}

The core of the hybrid instructional design is to use specific teaching and teaching methods for specific teaching content, and to use teaching content transmission techniques and methods to present teaching information. In college teaching, mixed teaching should create a positive and effective learning environment for learners, and teaching resources are the basis of learning environment. Therefore, Mixed teaching design should pay attention to how to provide necessary resources for learning activities.

The teaching design mainly includes the following four basic links. (1) Early analysis. Develop learning plans based on blended learning needs and learner characteristics, including learning content and learning objectives. (2) Learning resource design. Through the analysis of learning needs, learner characteristics, learning content and learning objectives in the early stage, design and develop the resources needed for course learning, including teaching courseware, MOOC videos, practice questions, and comprehensive cases. (3) Learning activity design. The activity process of student learning includes three stages: pre-class study, classroom study and after-school practice. (4) Teaching evaluation. The effect of the Mixed teaching mode is verified, and the mixed learning is evaluated more scientifically and rationally through the two factors of learning process and learning result. When evaluating the learning process, it mainly considers the positive level of students' participation in learning activities in the classroom, the performance in the activities, such as whether to ask questions when participating in group discussions and the completion of tasks in collaborative learning, etc. The evaluation mainly refers to the quality of the submitted work after the completion of the learning activity, the completion of the normal work, the data of the experimental report, the results of the final exam, and the results of the participation in the design competition.

\section{Mixed teaching implementation process}

From the above analysis, it is not difficult to see that the discussion of Mixed teaching only from the ADDIE instructional design model does not reflect the characteristics of Mixed teaching. Therefore, it is necessary to discuss the implementation process of the Mixed teaching, in order to provide a clearer operational process guidance and experience reference for college teachers to carry out mixed teaching.

Before the implementation of the Mixed teaching, teachers need to upload the self-learning task 
list that has been designed and produced and the online supporting curriculum resources with micro video as the core to the learning platform. The self-learning task list can be divided into three parts: 1 the study guide part, which can provide students with relevant information about the course and teaching, such as the teaching objectives, difficulties and suggestions of the learning methods in this section; 2 specific task parts, clear Students are required to complete the learning tasks related to the difficult teaching points by watching the micro video and applying related supporting resources. 3 In the confusion suggestion part, the students will submit the confusion encountered in the learning process to the learning platform, and the teacher can grasp the students before class. Autonomous learning and understanding of the student's problem in order to use the network or in the classroom teaching process to provide targeted answers and guidance. In short, the pre-course stage refers to the students using the relevant resources on the online learning platform to carry out independent learning according to the relevant content of the self-study task list, complete the tasks set by the teachers, and the related confusion encountered in the process of self-learning. And suggestions are submitted to the learning platform to form self-learning feedback before class; teachers use the discussion forum, chat room or QQ group, WeChat group and other network communication tools provided by the platform to communicate and feedback synchronously/asynchronously with students. Sexualized individualization guidance.

At the beginning of the course, the teacher can answer questions about the common problems that students have in the process of completing the task, using centralized teaching or organizing discussions. Individualized guidance that cannot be completed by the web platform can also be done in a face-to-face manner during the course. In the typical task exploration stage of the class, students can conduct research-based learning activities by means of independent inquiry or cooperative learning according to different inquiry questions. It is worth noting that in guiding students to conduct independent inquiry, teachers should respect the independence of individual students, construct their own knowledge system in the process of self-inquiry, and ensure that students can be assisted in a limited time. Large learning benefits. In guiding cooperative learning activities, teachers should not only give students the support and help of knowledge and skills, but more importantly, they should comprehensively use activities such as brainstorming and world cafes to mobilize the enthusiasm and initiative of students. At the same time, the instructor should give students the cooperative learning activities with methodological guidance and provide appropriate decision support services to ensure the smooth development of cooperative learning activities. After the self-exploration or cooperative learning activities are over, they will enter the stage of presentation and communication of the results in the class. In this process, students can display research learning results and share learning experiences and experiences through works exhibitions, time-limited speeches, and debates. In this process, teachers should not only comment and guide students' learning outcomes, but also guide students to reflect on the gains in knowledge and skills, and also guide students to reflect on the learning process, learning attitude, learning experience, and learning methods. Sum up and conduct self-evaluation to construct self-awareness.

\section{Conclusion}

Mixed teaching should be based on curriculum teaching, and integrate the emotional support, cognitive promotion and motivation of students into the design of teaching system. Based on classroom face-to-face and online teaching platform, students should provide appropriate metacognitive support and enhance students. The experience and learning effects of students in mixed teaching activities make the current mixed teaching theory more perfect and more learner-oriented. Of course, the quality of mixed teaching is determined by the elements of teaching activities. Therefore, in mixed teaching, we must fully consider the variability of various factors, the diversity of activities, and the differences between teachers and students. In the practice of mixed teaching in colleges and universities, we must constantly adjust, research, explore, summarize and optimize various factors, promote the continuous improvement of the quality of mixed teaching,

enhance the teaching effect, and strive to cultivate a strong independent innovation ability that meets the needs of social development. Comprehensive high-quality talents. 


\section{Acknowledgements}

Fund Project: 2017 Shandong Vocational Education Teaching Reform Research Project "Exploration and Research on Mixed Teaching Model of Preschool Education Major in Higher Vocational Colleges” (No. 2017649) Approved by: Department of Vocational Education, Shandong Provincial Education Department

\section{References}

[1] Zou Jingping. Successful Application Models and Examples of Mixed Learning in American Universities [J]. Distance Education in China, 2008, (11): 33.

[2] Zhang Sheng. Formative evaluation and theory and practice of learning activities under mixed learning environment [D]. Jilin: Northeast Normal University, 2008.

[3] Zhang Wei. Thoughts on Perfecting the Teaching Quality Evaluation System of Distance Education Teachers [J]. Modern Distance Education, 2008, (6).

[4] Xu Fuyin. Learning and Teaching in the Information Age [J]. Research in Audio-Visual Education, 2007, (12): 5-8.

[5] Li Gaoxiang. On the Necessity and Reality of Implementing Mixed Teaching Mode [J]. Modern Distance Education Research, 2006, (1): 22-23. 